\title{
A robótica educacional: entendendo conceitos
}

Railane Costa Santos raicostasantos@gmail.com 0000-0002-4692-4597 Universidade Estadual do Sudoeste da Bahia, Vitória da Conquista, Bahia, Brasil.

Maria Deusa Ferreira da Silva maria.deusa@uesb.edu.br 0000-0003-3462-3882

Universidade Estadual do Sudoeste da Bahia, Vitória da Conquista, Bahia, Brasil.

\begin{abstract}
RESUMO
O propósito deste artigo é apresentar, por meio de um estudo bibliográfico, o histórico da Robótica Educacional (RE), sob o ponto de vista Construcionista de Seymour Papert (19282016) e das interpretações de Valente (1948). Para tanto, primeiramente, é feita uma abordagem sobre as duas obras de Papert - LOGO: computadores e crianças e A Máquina das Crianças: repensando a escola na era da informática. Em seguida, apresentam-se a releitura de Valente sobre o Construcionismo - o construcionismo contextualizado e a espiral de aprendizagem. Na sequência, buscamos compreender o processo de criação e desenvolvimento de uma disciplina escolar proposta pelo próprio Papert, a Cibernética, hoje denominada por RE. E, por fim, apresentamos projetos, estudos e eventos que compõem o histórico da RE no Brasil e que nos permitem identificar os aspectos evolutivos, desde os primeiros estudos com o LOGO, na década de 1970, até os dias atuais.
\end{abstract}

PALAVRAS-CHAVE: Robótica Educacional. LOGO. Construcionismo. História. 


\section{INTRODUÇÃO}

Este texto trata-se se um recorte da pesquisa desenvolvida junto ao Programa de Pós-Graduação em Ensino Mestrado -PPGEn, da Universidade Estadual do Sudoeste da Bahia (UESB), que tem como objeto de estudo A "Robótica Educacional (RE) no contexto da Educação Especial". ${ }^{1}$

A Robótica Educacional (RE) tem estado cada vez mais presente no cotidiano das escolas do Brasil e do mundo como componente curricular ou extracurricular, atuando como elemento de incentivo tecnológico, integração social, inclusão digital e multidisciplinaridade. No entanto, o seu surgimento data na década de 1960, quando o seu idealizador, Seymour Papert, iniciou os seus estudos, no Instituto de Tecnologia de Massachussets (MIT), e deu vida ao ambiente LOGO.

O ambiente LOGO consiste em uma linguagem de programação pensada para iniciantes e um objeto, a "Tartaruga", físico ou cibernético. Para Papert, esse ambiente possibilitaria aos aprendizes refletirem sobre a própria forma de pensar, a fim de obter o máximo de conhecimento a partir do mínimo de ensino. Nessa perspectiva, e inspirado principalmente na Teoria Construtivista de Jean Piaget (1896-1980), Papert desenvolveu a filosofia de aprendizagem Construcionista, cujo objetivo é utilizar "objetos-de-pensar" e criar "ambientes verdadeiramente interessantes" (PAPERT, 1994, p. 125), também denominados, pelo autor, de micromundos, nos quais os educandos - de todas as idades - são os responsáveis pela própria aprendizagem, mediada pelo professor.

A fim de compreender melhor o Construcionismo, abordamos também, neste estudo, a perspectiva de José Armando Valente. Completando as ideias de Papert, Valente (1991) considera algumas características fundamentais dessa filosofia: as ações físicas e mentais que o aluno desenvolve ao longo do processo de aprendizagem, o ambiente em que se dá esse processo, o papel do professor como mediador e a consciência do aluno sobre a aprendizagem. Nesse sentido, Valente (2005) apresenta o que chama de Construcionismo Contextualizado - a construção do conhecimento com experiências práticas e o aprendiz inserido em um contexto significativo. $O$ autor ainda salienta a importância da utilização do computador nesse processo e desenvolve o ciclo e a espiral de aprendizagem, que consistem em diagramas representativos das etapas que acontecem quando o aluno está aprendendo por intermédio do computador na situação de programação.

Apesar de Valente apresentar ideias enfáticas sobre a situação de aprendizagem por intermédio da programação, consideramos que a RE possui outras etapas além desta. Por isso, a seção "Da Cibernética à RE: uma disciplina escolar para todos" é dedicada a entender como se deu o surgimento da RE como disciplina e quais são as ideias e conceitos envolvidos nesse processo.

A partir dos ideais do Construcionismo e dos estudos com ambiente LOGO nas escolas, Papert (1985) propõe a criação de uma disciplina escolar denominada, inicialmente, de Cibernética - atualmente, RE. O objetivo seria levar ao ambiente das crianças a Cibernética, isto é, a integração dos campos da Inteligência Artificial (IA) com os das demais áreas - Biologia, Psicologia, História, Filosofia, Matemática etc. Esse ideal deu origem à aliança LEGO-LOGO e aos kits de RE LEGO, MODELIX, PETE, ambientes de programação em blocos como Scratch e Snap! e a outras plataformas que podem ser utilizadas na mesma perspectiva, como o Arduino e seus semelhantes. 
O LOGO e os demais ambientes, embasados no Construcionismo, citados nesse artigo, são, desde o seu surgimento, amplamente utilizados como objetos de estudo em diversas partes do mundo. Segundo Moraes (1993), as primeiras pesquisas tiveram início em 1976, na Universidade Estadual de Campinas (UNICAMP), quando um grupo de professores, de Computação, Linguística e Psicologia Educacional, começou a investigar o uso dos computadores na educação, por meio de atividades que envolviam o uso do ambiente LOGO. Em seguida, em 1979, na Universidade Federal do Rio Grande do Sul (UFRGS), deu-se início às atividades do Laboratório de Estudos Cognitivos do Instituto de Psicologia, cujo objetivo foi explorar o potencial do computador por meio do uso da linguagem LOGO, prioritariamente com crianças da rede pública que possuíam dificuldade de aprendizagem. Desde então, inúmeras pesquisas vêm sendo realizadas com o objetivo de estudar as potencialidades, não apenas do ambiente LOGO, mas também das ferramentas que foram criadas a partir das ideias Construcionistas e que originaram a RE.

Mudanças significativas ocorreram no campo da RE: muitas escolas passaram a adotar a RE em seus currículos, sobretudo as da rede privada, o país passou a receber eventos que envolvem essas ferramentas, como o Scratch Day e o Torneio First Lego League (FLL), e houve uma transição dos trabalhos com o uso do LOGO para trabalhos com o uso de kits de RE.

Nessa perspectiva, a pesquisa da qual esse artigo faz parte agrega um dos campos da RE, a RE Inclusiva, que pouco explorado como recurso facilitador da aprendizagem. Sendo assim, busca-se compreender o contexto em que a RE foi pensada e quais são as características da filosofia de aprendizagem que a permeia, o Construcionismo.

Para tanto, este artigo se subdivide nas seguintes seções: A origem da RE: o LOGO; O Construcionismo de Seymour Papert; Construcionismo Contextualizado e a Aspiral de Aprendizagem, Da Cibernética à RE: uma disciplina escolar para todos; A popularização da RE através dos kits de robótica LEGO e outras plataformas e $A$ RE no Brasil: do LOGO aos dias atuais.

\section{A ORIGEM DA RE: O LOGO}

Para entender o que a RE representa hoje no mundo, é necessário revisitar a trajetória e as ideias do seu precursor, Seymour Papert. Para tanto, faremos uma abordagem dos seus dois livros, LOGO: computadores e educação e A Máquina das Crianças: repensando a escola na era da informática, lançados, respectivamente, nas décadas de 1980 e 1990, a fim de identificar quais eram as suas principais ideias e quais foram as conclusões encontradas em seus estudos com crianças de todas as idades.

Papert era matemático por formação; trabalhou com Jean Piaget durante cinco anos (1959-1964), período em que sua atenção esteve voltada para "crianças, a natureza do pensamento e como as crianças se tornam pensadores" (PAPERT, 1985, p. 244). Após essa temporada, mudou-se para Cambridge e passou a desenvolver seus estudos no MIT, o qual ele denominou de "mundo urbano de cibernética e computadores" (PAPERT, 1985, p. 244). Desde então, passou a focalizar a natureza do pensamento, em especial como fazer as máquinas pensarem, a Inteligência Artificial (IA). No entanto, Papert ainda carregava consigo 
questionamentos sobre a aprendizagem das crianças; para ele, Piaget apresentava a ideia de que elas aprendem muito mais sem serem ensinadas, mas dizia muito pouco "sobre como criar condições para que mais conhecimento pudesse ser adquirido pelas crianças através desse maravilhoso processo de "aprendizagem piagetiana"” (PAPERT, 1985, p. 252). A partir desse cenário, começou a formular duas ideias que permearam a primeira obra e que deram origem a sua trajetória como idealizador de um ambiente computacional para aprendizagem. São elas:

1) Mudanças significativas em padrões de desenvolvimento intelectual acontecerão através da mudança cultural; e 2) o mais provável condutor de mudanças culturais potencialmente relevantes no futuro próximo é a presença cada vez mais difundida do computador (PAPERT, 1985, p. 252).

Firmado nesses propósitos, em 1967, Papert começou a esboçar suas ideias para uma linguagem de programação que seria apropriada para crianças, a LOGO. Para ele, o ideal seria uma linguagem com o poder das linguagens profissionais (como C, C++, Phyton, Java etc), mas com fáceis vias de acesso para principiantes sem domínio da Matemática. Sobre a Matemática, o autor sempre a enfatiza em suas obras, e está claro que, em seus estudos e experimentos, esta é a principal disciplina trabalhada e que o foco é a sua aprendizagem. No entanto, Papert (1985) apresenta, em LOGO: computadores e educação, além da aprendizagem matemática, outras vantagens e objetivos de se trabalhar com a nova linguagem, como : sentimento de domínio sobre modernos e poderosos equipamentos tecnológicos; maior intimidade com ideias da ciência, Matemática e construção de modelos intelectuais; as crianças passam a explorar a própria maneira de pensar; as crianças percebem que as coisas funcionam em um contínuo, não estando necessariamente certas ou erradas; as crianças aprendem que o professor também é um aprendiz; e as crianças transferem hábitos da vida real para a construção de teorias científicas.

Todas essas vantagens estão atreladas a críticas feitas pelo autor à cultura e ao ensino da escola tradicional à época - que se perpetuam, em alguns lugares do mundo, até os dias de hoje. Por exemplo: a cultura de aptidões e inaptidões, que rotulam os estudantes como "matemáticos" ou "não matemáticos, "artísticos" ou "não artísticos" etc; a divisão do conhecimento em "Humanas" e "Exatas" e a classificação das pessoas como inteligentes para uma dessas áreas; e o modelo de aprendizagem matemática via "decoreba", em que o material é tratado como sem sentido pelo aprendiz. (PAPERT, 1985).

A fim de romper com todos esses paradigmas e agregar as vantagens citadas pelo autor, não apenas uma linguagem de programação foi criada, mas o ambiente LOGO, composto pela linguagem e por uma tartaruga cibernética. A primeira versão (1968-1969) não possuía a parte gráfica: "os alunos escreveram programas que transformaram inglês em "Pig Latin", programas para jogos de estratégia, e outros ainda que criavam poesia concreta" (PAPERT, 1985, p. 26). Contudo, segundo a Fundação LOGO (2015), o ambiente mais popular do LOGO envolveu a Tartaruga (Turtle), cuja representação poderia ser abstrata nas telas dos computadores ou objeto lúdico físico que poderia andar e ser tocado, conforme mostra a Figura 1, em que crianças interagem com o objeto. 


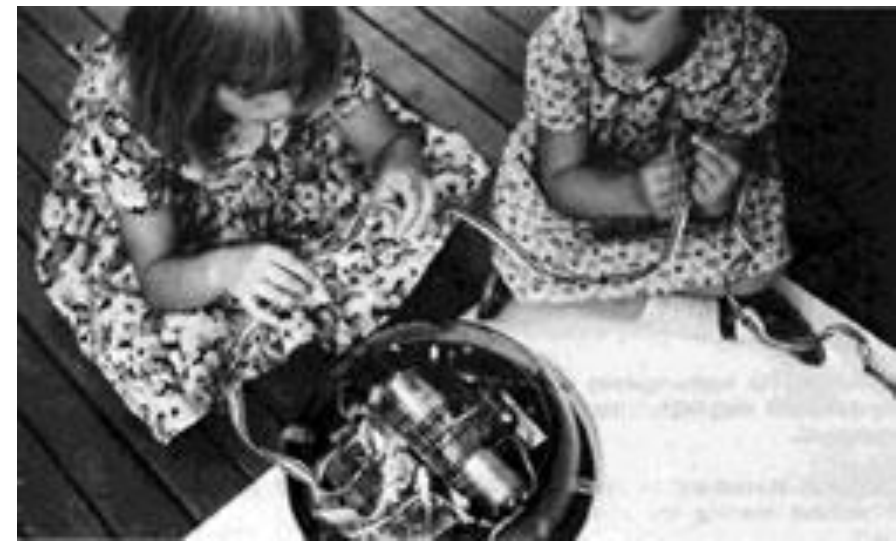

Fonte: Fundação LOGO (2015).

Nesse sentido, o objeto Tartaruga, intangível (virtual) ou tangível (físico), foi criado sob a perspectiva de ser um "objeto-de-pensar-com", cujo objetivo foi fazer com que as crianças se apropriassem à sua própria maneira e partiu da experiência que o próprio Papert tivera com as engrenagens (objetos físicos) que serviram como instrumentos para sua aprendizagem matemática. A LOGO, por sua vez, foi criada para ser uma linguagem de programação simples, fácil de ser programada e possui comandos que fazem a Tartaruga se movimentar e deixar o rastro formando, por exemplo, as imagens geométricas que as crianças desejassem.

O fato de a Tartaruga servir como objeto de aprender Geometria originou "Tartaruga-Geométrica", um dos primeiros micromundos do ambiente LOGO: "suas propriedades essenciais - posição, orientação e habilidade de obedecer a comandos na 'língua da tartaruga' são mais importantes para se fazer geometria." (PAPERT, 1985, p. 78).

Além da Tartaruga-Geométrica, outros micromundos foram criados para aprendizagens diversas ligadas ou não ao currículo escolar. Todavia, Papert também deu ênfase a outras aprendizagens paralelas, como a "filosofia do debbuging", em que as crianças são incentivadas a corrigir os erros ao invés de apagar um programa inteiro, e, desse modo, rompe-se o paradigma imposto pelas escolas de que errar é mau, de forma que a criança passe a utilizar a situação como uma oportunidade de entender melhor os seus pensamentos, ações e conceitos. Diante disso, Papert desenvolveu uma filosofia educacional, o Construcionismo, a qual ele diz ser sua "reconstrução pessoal do Construtivismo" de Jean Piaget (PAPERT, 1994, p. 127) e que será tratada na próxima seção.

\section{O CONSTRUCIONISMO DE SEYMOUR PAPERT}

Em primeiro lugar, é necessário saber o que há de comum entre o Construcionismo de Papert e o Construtivismo de Piaget que tem foco na ideia de concretude ou pensamento concreto. Para Piaget (1971), a aprendizagem das crianças se dá em quatro estágios: sensório-motor, pré-operatório, operacional concreto e operacional formal. Papert dá ênfase ao terceiro estágio, que, segundo Piaget (1971), abrange dos cinco aos 12 anos de idade e está relacionado à capacidade de abstrair dados da realidade; nesse estágio, "as operações 'concretas' recaem diretamente sobre os objetos: isto equivale a agir sobre eles 
[...] conferindo a essas ações [...] uma estrutura operatória, isto é, componível de maneira transitiva e reversível." (PIAGET, 1971, p. 149). Para Papert, as práticas que envolvem a ideia de construção mental, a partir de experiências reais, não devem se restringir a essa faixa, mas permear todos os níveis escolares. Nas palavras de Papert:

Minha estratégia é fortalecer e perpetuar o processo concreto típico até mesmo na minha idade. Ao invés de pressionar as crianças a pensarem como adultos, poderíamos fazer melhor lembrando-nos que elas são grandes aprendedores e tentar arduamente nos tornar mais parecidos com elas (PAPERT, 1994, p. 137-138).

Nesse sentido, o Construcionismo é uma filosofia educacional que propõe a valorização do concreto ao invés do ensino abstrato e, além disso, coloca o professor como mediador e o aprendiz como construtor do próprio conhecimento. Com isso, visa a romper com as práticas meramente instrucionistas em que o professor detém o conhecimento e o repassa para os educandos - "a meta é ensinar de forma a produzir a maior aprendizagem a partir do mínimo de ensino." (PAPERT, 1994, p. 125).

A fim de compreender melhor o Construcionismo e suas diferentes abordagens, consideraremos as interpretações de José Armando Valente ${ }^{2}$ sobre o Construcionismo e a utilização dos objetos-de-pensar no processo de aprendizagem. Nessa perspectiva, Valente (1991, p. 57) faz considerações sobre o Construcionismo de Papert: "é diferente do instrucionismo no sentido em que a ênfase é no aprendizado e não no ensino", de modo que sejam oferecidas condições para que o aluno aprenda. Diante disso, Valente (1991, p. 57) apresenta dois aspectos que são de fundamental importância no Construcionismo: "a ação física ou mental do aprendiz e o ambiente onde está inserido".

\footnotetext{
O ambiente deve ser o mais interessante possível, a fim de poder ser apropriado pelo aprendiz. Deve ser rico em atividades, conceitos e coisas para serem feitas. $\mathrm{O}$ ambiente deve ser constantemente motivador e interessante, cabendo ao professor a tarefa para que isso realmente aconteça (VALENTE, 1991, p. 57).
}

Ainda para o autor, o professor deve ser o facilitador ou consultor do processo de aprendizagem, sendo capaz de identificar a capacidade cognitiva do aluno e propor atividades que estejam de acordo com o nível de cada um. Além disso, o professor precisa de aparatos que proporcionem a realização dessas atividades, tomando como exemplo a metodologia LOGO de aprendizado que apresenta "o computador como esta ferramenta versátil para acomodar os diferentes interesses e capacidades intelectuais de seus usuários." (VALENTE, 1991, p. 59).

Desse modo, tomando como base as considerações dos autores, podemos elencar as principais características propostas pela filosofia Construcionista: a) Criar ambientes (micromundos) verdadeiramente interessantes, apropriados para o aprendiz; b) Disponibilizar aparatos que tornem o ambiente interessante e estimulem os indivíduos a construírem o conhecimento, como o computador; c) Proporcionar experiências reais que façam sentido para o aprendiz; d) Garantir que os indivíduos executem ações físicas ou mentais de modo que se tornem construtores do próprio conhecimento; e) Garantir que o aluno tome consciência do conhecimento envolvido na atividade realizada. 
O Construcionismo, portanto, é uma filosofia de aprendizagem prática que partiu da ideia da utilização do ambiente LOGO, que deu origem a diversas outras ferramentas utilizadas em ambientes escolares ou não, mas que, sobretudo, dão subsídio à construção do conhecimento por intermédio do uso do computador, por meio de uma linguagem de programação, como objeto de pensar. Por esse motivo, a próxima seção traz a abordagem de Valente (2005) sobre o uso do computador como ferramenta de aprendizagem.

\section{O CONSTRUCIONISMO CONTEXTUALIZADO E A ESPIRAL DE APRENDIZAGEM}

Apesar de Papert citar o seu envolvimento com o Construtivismo de Piaget para desenvolver o Construcionismo, Valente (2005, p. 55-56) cita duas ideias que diferenciam essas duas teorias, afirmando que na perspectiva Construcionista "o aprendiz constrói um produto, ou seja, a construção do conhecimento é baseada no fazer, no "colocar a mão na massa"" e "o fato de o aprendiz estar construindo algo significativo, do seu interesse e para o qual ele está bastante motivado". Além disso, Valente $(2005$, p.56) afirma que a presença do computador é um "fator fundamental para a diferença entre essas duas maneiras de construir o Conhecimento".

Nesse sentido, Valente dedica parte dos seus estudos a entender e explicar como funciona o processo de aprendizagem por intermédio do computador como objeto-de-pensar, em especial no processo de programação. Num primeiro momento, Valente se dedica a desenvolver o que chamou de Ciclo de Ações na interação aprendiz-computador.

Para Valente (1999), a aprendizagem por intermédio do computador se dá em diferentes etapas: descrição-execução-reflexão-depuração-descrição. A descrição é a etapa em que o aprendiz (sujeito), em uma sequência de comandos, informa ao computador o que deve ser feito para a solução de um determinado problema. A fase seguinte é a de execução, em que o computador (objeto) realiza os procedimentos descritos pelo sujeito, apresentando um resultado. $O$ sujeito diante de tal resultado faz uma reflexão sobre o que está vendo, em caso de identificação de resultados diferentes da intenção do sujeito, acontece a etapa de depuração, em que o sujeito busca por novas informações sobre conteúdos ou estratégias de resolução (momento em que há aquisição de novos conhecimentos) e desse modo, passa-se para uma nova descrição.

No entanto, o autor agrega a esse ciclo de aprendizagem, dois outros quesitos: o fato de as ações acontecerem em um ambiente social, à luz da perspectiva Freiriana, em que este seria "fonte de ideias, de conhecimento ou de problemas a serem resolvidos através do uso do computador" (VALENTE, 1999, p. 75) e o fato de haver a presença do mediador, como o agente que entende sobre a linguagem de programação, "tanto do ponto de vista computacional, quanto do pedagógico e do psicológico" (VALENTE, 2005, p. 54). A figura 2 (a) ilustra o ciclo de ações, conforme a descrição. 
Figura 2 - Interação aprendiz-aluno na situação de programação

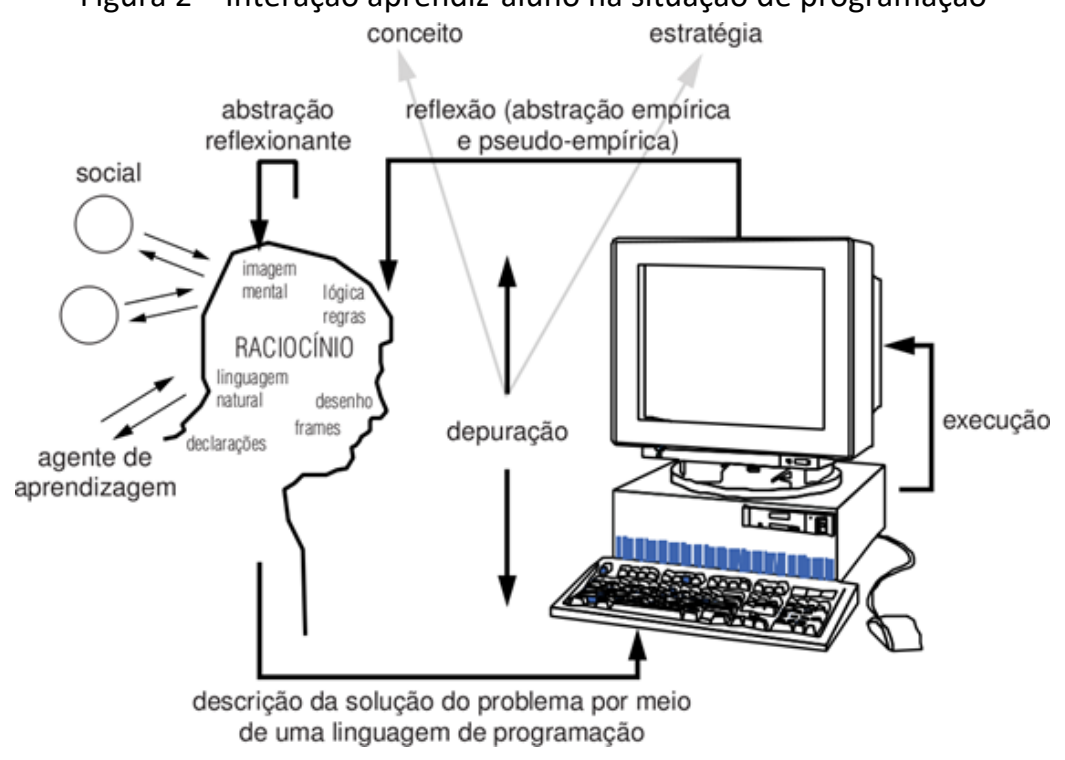

Fonte: Valente (1999).

A junção de várias teorias para explicar as ações que delimitam a aprendizagem intermediada pelo computador levou Valente ao que chamou de "construcionismo contextualizado" expressão que para Valente $(2005$, p.55) pode ser compreendida pelas definições: "construcionismo - o aprendiz engajado na construção de um produto significativo, usando a informática; e contextualizado o produto construído relacionado com a realidade do aprendiz" de modo a abordar a teoria de Papert e a contextualização do conhecimento em um meio social, proposta por Vygostsky e Paulo Freire. Desse modo, Valente explicita essa abordagem pelo diagrama a seguir.

Figura 3 - Teóricos cujas contribuições ajudam a explicar o ciclo de ações

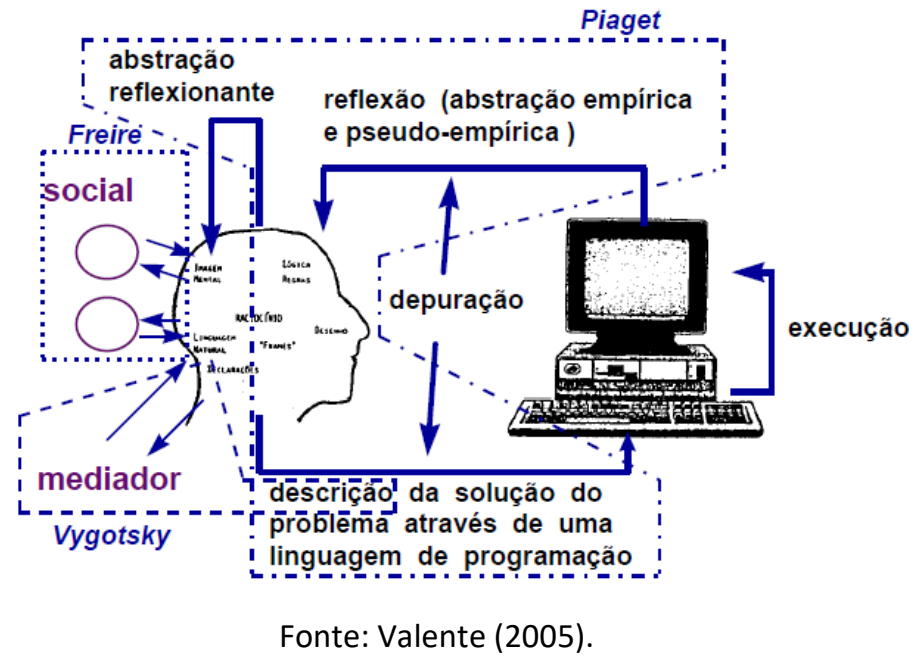

Nesse diagrama da Figura 3, Freire foi identificado com o aspecto social (linhas pontilhadas), Vygotsky com a descrição da solução do problema e com a mediação (linha tracejada), Piaget com as reflexões e com a descrição da solução do problema através de uma linguagem de programação (linha com ponto e traço) (VALENTE, 2005, p. 58). 
Nesse ponto, consideramos fazer uma descrição muito singela sobre o papel das abordagens Vygotsky e Paulo Freire nesse esquema feito por Valente. Vygotsky contribui com o aspecto teórico da mediação, levando-se em consideração que, para existir a aprendizagem, é necessária a atuação dos pares, colegas e professores, mais experientes, como mediadores. Quanto a Paulo Freire, Valente (2005) destaca que

O aspecto social foi incluído por conta de um trabalho que estava sendo realizado pelo Nied junto à Secretaria de Educação do Município de São Paulo, como assessoria ao grupo que estava implantando a informática na educação. O secretário nessa época era Paulo Freire, de modo que era muito importante o aspecto do trabalho com a comunidade, da identidade cultural. Assim, a comunidade deveria ser a fonte dos problemas a serem resolvidos por intermédio do computador, e as soluções e os conhecimentos adquiridos pelo aprendiz deveriam retornar à comunidade, na forma de alguma melhoria a ser implantada (VALENTE, 2005).

No entanto, apesar de ter utilizado por muito tempo ciclo, Valente propõe uma diferenciação movido pela seguinte questão: "Como algo cíclico, repetitivo, como um ciclo pode explicar algo crescente como a construção do conhecimento?" (VALENTE, 2005, p. 64). Nesse sentido, surge então a concepção da espiral de aprendizagem na interação aprendiz-computador, que considera que "a cada ciclo completado, as ideias do aprendiz deveriam estar em um patamar superior do ponto de vista conceitual" (VALENTE, 2005, p. 66).

Sendo assim, a nova representação está no diagrama a seguir:

Figura 4 - Espiral da aprendizagem que acontece na interação aprendiz-computador

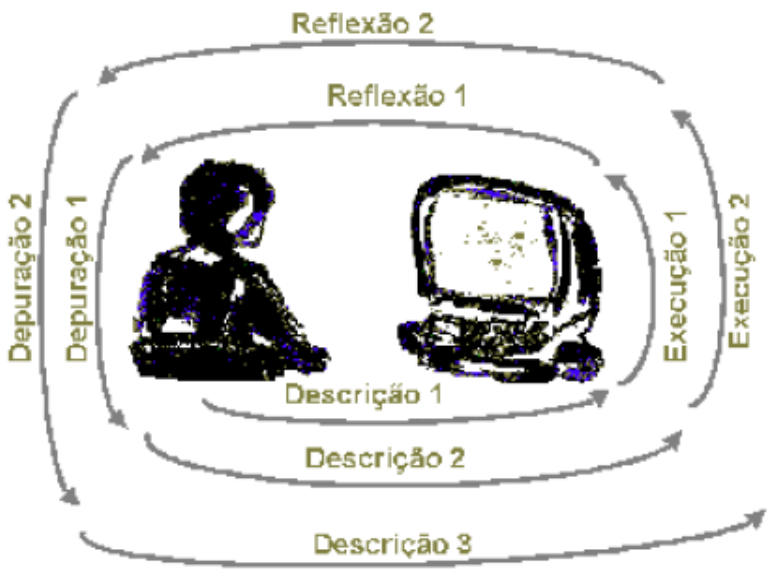

Fonte: Valente (2005).

Nesse sentido, o diagrama da figura 4 mostra que o ciclo não deixa de existir, mas acontece uma continuidade dele incrementada por novos conhecimentos adquiridos na etapa anterior pelo aprendiz.

As interpretações de Valente acerca do Construcionismo e as suas contribuições para a análise do processo de aprendizagem que acontece com a interação aprendiz-máquina, portanto, nos permite conhecer com mais detalhes como se dá esse processo, dando subsídio a análises feitas a partir de experiências com a Robótica Educacional como ferramenta de ensino e aprendizagem. No entanto, apesar de Valente dedicar-se a explicar como se dá o processo de interação aprendiz-computador, não podemos nos ater a apenas isso quando 
falamos da Robótica Educacional, pois esta agrega muitos outros elementos além do computador, sendo assim, dedicaremos a próxima sessão a explicar como essa disciplina escolar surgiu e quais são esses elementos.

\section{DA CIBERNÉTICA À ROBÓTICA EDUCACIONAL: UMA DISCIPLINA ESCOLAR PARA TODOS}

A partir da filosofia Construcionista, Papert propõe a criação de uma nova "disciplina", que ofereça, na escola, todo o aparato proposto por sua filosofia e que, para ele, será de grande valia para os jovens. A princípio, sugeriu que o nome fosse "Engenharia de Controle" ou "Robótica", mas, pela capacidade que a disciplina teria, não apenas de oferecer aos estudantes a possibilidade de engajarse com o campo da Inteligência Artificial, mas de fazer conexões com outras áreas do conhecimento, como Biologia, Psicologia, Economia, História e Filosofia, optou por chamá-la de "Cibernética para crianças". Para Papert, o termo "cibernética" apresenta significado mais amplo que os demais, uma vez que inclui duas características do seu propósito ao propor essa disciplina: "desenvolver um arcabouço no qual as crianças poderiam engajar-se com a inteligência artificial elementar" e "o uso da tecnologia como meio para representar comportamentos que se pode observar em nós mesmos e em outras pessoas" (PAPERT, 1994, p. 160). Ainda para o autor, "A troca de IA para a Cibernética amplia o foco dos protótipos de comportamento com um sabor principalmente lógico, para incluir protótipos com sabor mais biológico." (PAPERT, 1994, p. 160-161).

Para Papert, a questão passou a ser: ao invés de atrair as crianças para o mundo cibernético das Tartarugas, colocar a Cibernética no mundo das crianças. Para tanto, uma aliança história no mundo dos "computadores na escola" formouse no final da década de 1980: a LEGO-LOGO, uma colaboração entre o MIT Media Lab e a empresa de brinquedos de montar LEGO. Segundo a Fundação LOGO (2015), a parceria LEGO-LOGO atingiu milhares de professores e alunos e alavancou a uma série de conferências e projetos com o LOGO, incluindo disciplinas obrigatórias no currículo nacional em escolas da Inglaterra, por exemplo.

\footnotetext{
As crianças amam construir coisas, então escolhemos um conjunto de construção e acrescentamos-lhe o que quer que seja necessário para tornalos modelos cibernéticos. Elas deveriam ser capazes de fazer uma tartaruga com motores e sensores e ter uma forma de escrever programas em LOGO para guiá-las (PAPERT, 1994, p. 173).
}

Desse modo, o LEGO-LOGO concretizou as ideias de Papert, trazendo consigo outro aspecto importante do ambiente LOGO, a possibilidade de feedback rápido para o aprendiz, no sentido de se obter uma resposta imediata sobre o que é produzido, ou seja, se está apresentando o resultado desejado ou não. Assim, o LEGO-LOGO disseminou o que Papert denominou de Cibernética e tem estado presente até os dias de hoje em grande parte das escolas do mundo. No entanto, atualmente tem sido utilizado o termo RE para esta prática nas escolas e fora delas, além de ser objeto de estudo de muitos pesquisadores. Pensando em compreender melhor o conceito de RE, buscamos algumas definições do termo: Para Silva (2009, p. 32), a robótica educacional caracteriza-se por um ambiente de trabalho, em que os alunos terão a oportunidade de montar e programar seu 
próprio sistema robótico, controlando-o através de um computador com software especializados. Marcão (2017) compartilha da ideia de que robótica educativa é um ambiente de aprendizagem, no qual os alunos têm um papel ativo na construção do seu próprio conhecimento, através da montagem, programação e controlo do seu próprio artefato robotizado. (GONÇALVES; FREITE apud MARCÃO, 2017). E ainda, o dicionário interativo da educação define RE como

Termo utilizado para caracterizar ambientes de aprendizagem que reúnem materiais de sucata ou kits de montagem compostos por peças diversas, motores e sensores controláveis por computador e softwares que permitam programar de alguma forma o funcionamento dos modelos montados (MENEZES; SANTOS, 2015).

Assim, entendemos como RE o ambiente que oferece aparatos para que os alunos aprendam, de forma multidisciplinar, por meio da montagem e programação de protótipos robóticos e, além disso, desenvolvam competências como pensamento científico, crítico e analítico, cultura digital, responsabilidade e cidadania. Ademais, tomando por base as ideias dos autores acerca do assunto, sugerimos que o processo de aprendizagem por meio da RE possa ainda ser dividido em três etapas: planejamento, execução (montagem e programação) e reflexão.

O planejamento é feito pelo aluno assim que o professor mediador lhe propõe o desafio. Nessa etapa, o aluno deve escolher as melhores estratégias para montagem e programação de um protótipo. Algumas vezes, quando lhe é fornecido um manual de montagem, essa etapa pode encurtar-se, uma vez que o manual já lhe oferece informações pré-estabelecidas para montagem. A execução abarca as ações de montar e programar o protótipo. E, por fim, na etapa de reflexão, o aluno pode analisar os resultados do seu trabalho, a fim de conhecer acertos e erros, estes últimos podem leva-lo de volta para a primeira etapa, a de planejamento, para traçar novas estratégias para a correção.

Conhecendo os conceitos por trás da RE, buscamos identificar alguns exemplos de aparatos que dão subsídio a utilização dessa ferramenta nas salas de aula, sendo assim, a próxima seção se dedica tais aparatos e a popularização da robótica por meio destes.

\section{A POPULARIZAÇÃO DA ROBÓTICA EDUCACIONAL ATRAVÉS DOS KITS DE ROBÓTICA LEGO E OUTRAS PLATAFORMAS}

Desde o seu surgimento, o LEGO-LOGO vem passando por diversas atualizações. Em sua primeira versão, a LEGO TC LOGO - 1987, os motores e sensores recebiam instruções por meio de fios conectados ao computador (Figura 5). No entanto, segundo a Fundação LOGO (2015), a partir da segunda versão, o Brick (Bloco) Programável (Lançado em 1998) ou RCX, os computadores cabiam dentro dos próprios modelos, "agora a inteligência realmente está no modelo ao invés de um computador fora de escala" (PAPERT, 1994, p. 173). Além disso, a cada nova versão o ambiente passava a ser ainda mais facilitado para o usuário. Como parte do projeto Brick Programável, "uma nova versão do LOGO chamada LOGO Blocks foi criada. Em vez de escrever linhas de código em texto, os programas foram construídos ao juntar peças semelhantes a quebra-cabeças" (LOGO 
FUNDATION, 2015). Na sequência, em 2006, foi lançado o Lego Mindstorm NXT e em 2013 foi lançado o Lego Mindstorm EV3, versão mais atual (LEGO, 2018).

Figura 5 - Versões dos Kits de Robótica Lego

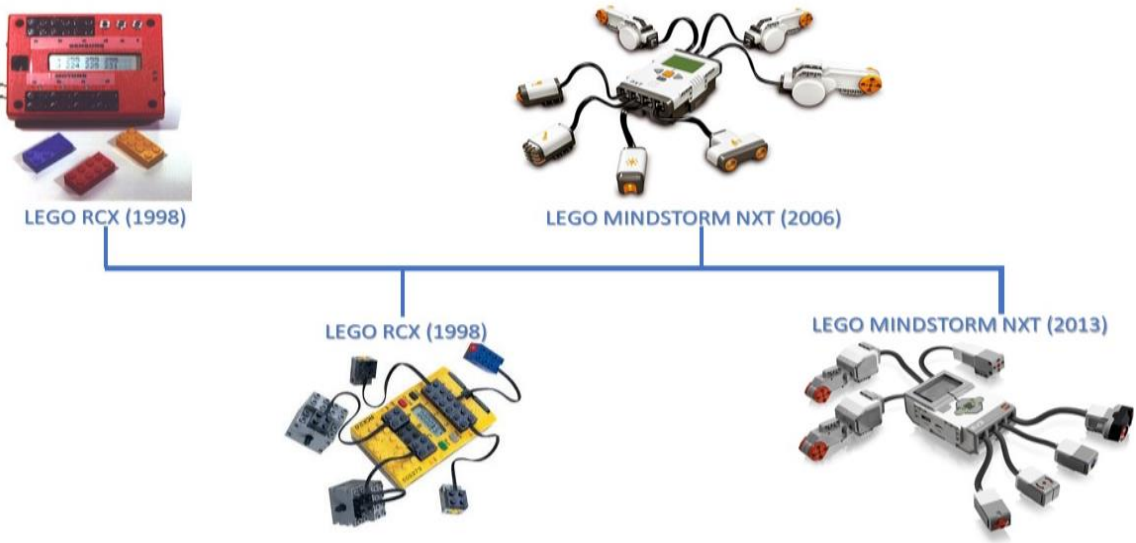

Fonte: Autoria Própria (2018).

Apesar de os Kits Lego de Robótica serem os mais difundidos no mundo e ter dado o merecido respaldo ao LOGO e às ideias de Papert, outras plataformas, física e/ou abstratas, foram criadas com a mesma finalidade educacional proposta pelo Construcionismo.

Quanto às plataformas físicas, podemos citar outros kits de robótica semelhantes aos da LEGO, como o PETE, comercializado a partir de 2005 (PETE, 2017), e o Modelix, comercializado há mais de 10 anos (MODELIX ROBOTICS, 2018). No entanto, existem também as plataformas de código aberto criadas com finalidade educacional, como o Arduino e seus semelhantes (Ex.: Parallax Basic Stamp, o BX-24 da Netmedia, o Phidgets, o Handyboard do MIT).

O Arduino não é necessariamente uma derivação do Ambiente LOGO, mas possibilita que uma infinidade de trabalhos seja realizada na mesma perspectiva e oferece diversas vantagens, por isso popularizou ainda mais os ambientes de Cibernética/Robótica propostos por Papert. Portanto, acrescentamos essa plataforma na lista de ambientes construcionistas de aprendizagem. A plataforma se destaca por possuir diversas vantagens e possibilitar que tanto iniciantes quando programadores profissionais como alunos, professores e amadores o utilizem para projetos de prototipagem eletrônica: barato, plataforma cruzada (pode ser executado em diversos sistemas operacionais), ambiente de programação simples e claro, software open source e extensível e hardware open source e extensível (ARDUINO, 2019). Por esses motivos, o Arduino pode e tem substituído os kits de robótica pré-fabricados em muitos projetos por oferecer todas essas vantagens e, em especial, por possibilitar ambientes de aprendizagem de baixo custo para quem quer que esteja disposto a aprender.

Além dos ambientes físicos de aprendizagem, o LOGO também foi modelo para outros softwares educacionais, a exemplo o Scratch, um ambiente de programação LOGO, com linguagem em blocos, surgido em 2004, totalmente gratuito, também criado no MIT Media Lab, pelo Grupo Lifelong Kindergarten: "Scratch é bem adequado para projetar e construir histórias interativas, animações, jogos, música e arte. Ele pode coletar informações do mundo externo 
por meio de uma placa de sensores conectada ao computador." (LOGO FUNDATION, 2015).

A linguagem Scratch deu origem a outros ambientes como o Snap!, o S4A (Scratch for Arduino) e o S2A (Scratch to Arduino), que ganharam aparatos que possibilitam a programação simplificada, através de linguagem em blocos, para o Arduino, de modo que os motores e sensores conectados à plataforma podem ser manipulados pelo usuário via blocos de programação. Nesse sentido, para seus idealizadores os objetivos foram dois: atrair pessoas para o mundo da programação e fornecer uma interface de alto nível para os programadores do Arduino com funcionalidades como interagir com um conjunto de placas através de eventos do usuário (CITILAB, 2015).

Figura 6 - Ambiente S4A

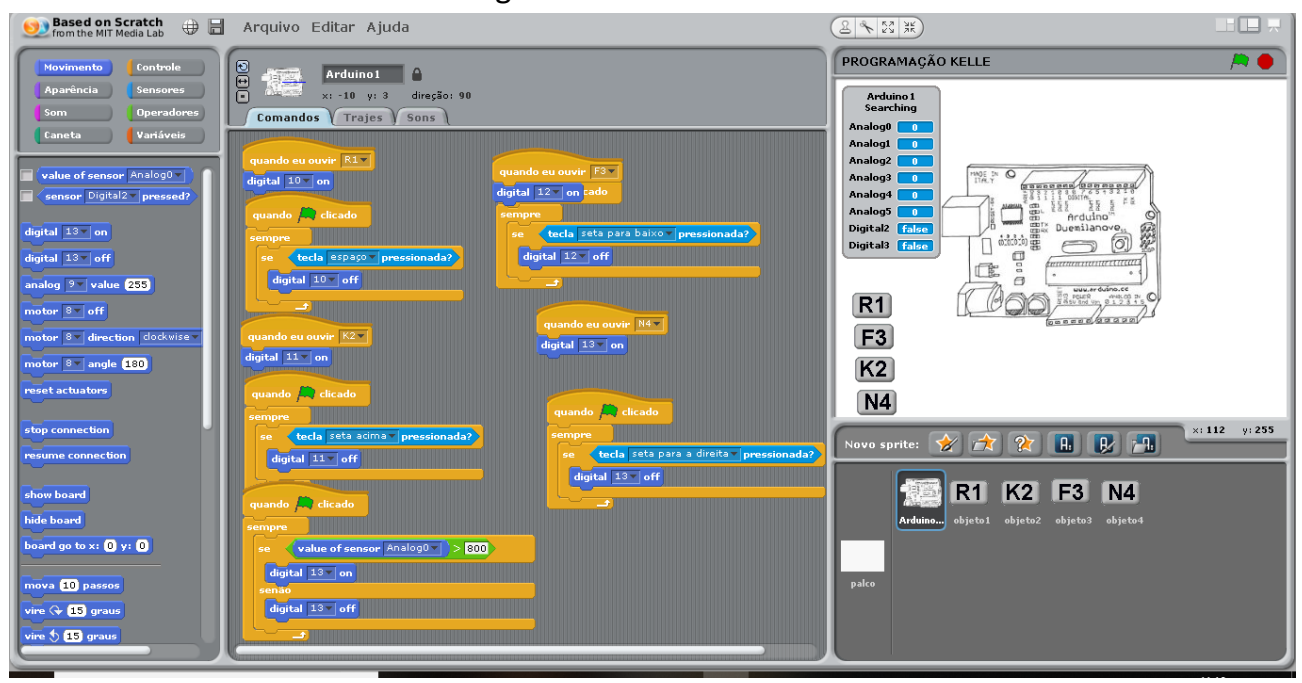

Fonte: Autoria Própria (2018).

Como visto, existem diversos ambientes que possibilitaram a popularização da Robótica Educacional em todas as partes do mundo. Desde o seu surgimento, diversos pesquisadores têm se dedicado a estudar os seus benefícios em todas as partes do mundo, não sendo diferente no Brasil, por esse motivo, dedicamos a próxima seção a uma linha do tempo que traça a sua trajetória na educação brasileira.

\section{A ROBÓTICA EDUCACIONAL NO BRASIL: DO LOGO AOS DIAS ATUAIS}

Tendo em vista a grande quantidade de ações, públicas ou não, desenvolvidos durante a trajetória da RE no Brasil, essa seção visa a apresentar algumas dessas ações. Iniciando com os primeiros estudos, a partir do LOGO até a RE dos dias atuais, traçamos uma linha do tempo, incluindo iniciativas públicas e privadas de implantação e desenvolvimento de práticas ligadas à RE. $O$ quadro 1 resume as principais informações encontradas a respeito do tema, retiradas de diferentes fontes, como noticiários, páginas institucionais, páginas governamentais e artigos científicos. 
Quadro 1 - Linha do tempo da RE no Brasil

\begin{tabular}{|c|c|}
\hline Ano & Acontecimento \\
\hline 1976 & $\begin{array}{l}\text { Início das atividades do Primeiro Grupo de Pesquisa com o LOGO - } \\
\text { Universidade Estadual de Campinas -UNICAMP/SP. (MORAES, 1993) }\end{array}$ \\
\hline $1979 / 1980$ & $\begin{array}{l}\text { Início das atividades de pesquisa para investigação dos processos } \\
\text { cognitivos dos estudantes em situações de aprendizagem em interação } \\
\text { com o computador utilizando a Linguagem LOGO do Laboratório de } \\
\text { Estudos Cognitivos (LEC) da Universidade Federal do Rio Grande do Sul - } \\
\text { UFRGS. (FERNANDES; SANTOS, 1999) }\end{array}$ \\
\hline 1983 & $\begin{array}{c}\text { Criação do Projeto EDUCOM e do Núcleo de Informática Aplicada à } \\
\text { Educação (NIED), que tem o LOGO como um dos principais objetos de } \\
\text { estudo - UNICAMP/SP. (VALENTE, 1991) }\end{array}$ \\
\hline 1985 & $\begin{array}{l}\text { Início do projeto EDUCOM com atividades com o LOGO em outras } \\
\text { instituições - Universidade Federal de Pernambuco - UFPE, Universidade } \\
\text { Federal de Minas gerais (UFMG), Universidade Federal do Rio de Janeiro - } \\
\text { UFRJ, UFRGS e UNICAMP/SP. (VALENTE, 1991) }\end{array}$ \\
\hline 1985 & $\begin{array}{l}\text { Início do Projeto Uso da Informática na Educação Especial, com atividades } \\
\text { utilizando o ambiente LOGO - UFPE, UFMG, UFRJ, UFRGS e UNICAMP/SP. } \\
\text { (VALENTE, 1991) }\end{array}$ \\
\hline & $\begin{array}{l}\text { Tradução do livro LOGO: Computadores e Educação para o Português - } \\
\text { UNICAMP/SP. (CHAVES, 2015) }\end{array}$ \\
\hline \multirow[t]{2}{*}{1986} & $\begin{array}{l}\text { Primeiro Congresso Brasileiro LOGO: Informática na Educação - Novo } \\
\text { Hamburgo/RS. (SANTAROSA, [200-?]) }\end{array}$ \\
\hline & $\begin{array}{l}\text { Início das atividades do Projeto EDUCOM nas escolas - Brasil. (VALENTE, } \\
\text { 2006) }\end{array}$ \\
\hline 1987 & Início do Projeto Robótica Pedagógica - UNICAMP/SP. (NIED, [20--?]) \\
\hline 1988 & Segundo Congresso Brasileiro LOGO - Petrópolis/RJ (SANTAROSA, [200-?]) \\
\hline 1989 & $\begin{array}{l}\text { Primeira Oficina LEGO-LOGO, com Stephen } \text { Ocko }^{3} \text {, foi realizada no NIED } \\
\text { UNICAMP/SP. (NIED, [20--?]) }\end{array}$ \\
\hline 1993 & $\begin{array}{l}\text { O Laboratório de Estudos Cognitivos da UFRGS adquiriu o primeiro } \\
\text { material de robótica destinado a crianças, o LEGO TC LOGO. - (LOPES, } \\
\text { 2008). }\end{array}$ \\
\hline 1995 & $\begin{array}{l}\text { Lançamento do Kit Educacional Multimídia SuperLogo - UNICAMP/SP. } \\
\text { (Super logo, [20--?]) }\end{array}$ \\
\hline 1996 & $\begin{array}{l}\text { Registro mais antigo de dissertação com o tema RE no Catálogo de Teses e } \\
\text { Dissertações da CAPES: "Processos cognitivos de professores num } \\
\text { ambiente construtivista de robótica educacional”, de Paulo Petry Padilla - } \\
\text { UFRGS. (CAPES, 2019) }\end{array}$ \\
\hline 1998 & $\begin{array}{l}\text { Primeiro registro de dissertação com a proposta de criação do primeiro } \\
\text { Laboratório Virtual de Robótica para ensino e aprendizagem de Robótica, } \\
\text { de Luciano Rodrigues de Queiróz - UNICAMP/SP. (QUEIROZ, 1998) }\end{array}$ \\
\hline 2000 & $\begin{array}{l}\text { Início de um aumento considerável das pesquisas no campo da RE } \\
\text { registradas na Biblioteca Digital Brasileira de Teses e Dissertações e } \\
\text { redução dos registros de pesquisa com o ambiente } \text { LOGO }^{3} \text {. }\end{array}$ \\
\hline 2001 & $\begin{array}{l}\text { Criação do Grupo de Inteligência Artificial da Faculdade de Computação da } \\
\text { Universidade Federal de Uberlândia - UFU, com um dos objetivos voltados }\end{array}$ \\
\hline
\end{tabular}




\begin{tabular}{|c|c|}
\hline & $\begin{array}{l}\text { para aplicar Robótica Educativa no Ensino de Matemática e Ciências - MG. } \\
\text { (LOPES, DORÇA, et al., 2014) }\end{array}$ \\
\hline 2004 & $\begin{array}{l}\text { Primeira vez que o Brasil participou do Torneio de Robótica First Lego } \\
\text { League (FLL) - PE. (PERNAMBUCO, 2011) }\end{array}$ \\
\hline 2011 & $\begin{array}{c}\text { Criação do projeto ROBO+EDU, da UFRGS em parceria com o programa } \\
\text { Mais Educação do Ministério da Educação (MEC) para capacitação e } \\
\text { formação continuada de professores e profissionais da Educação Básica - } \\
\text { UFRGS. (UFRGS, [201-?]) }\end{array}$ \\
\hline \multirow[t]{3}{*}{2014} & Criação da comunidade Scratch Brasil - Brasil. (MIT MEDIA LAB, 2019) \\
\hline & $\begin{array}{l}\text { Primeira vez que o Brasil sediou o Torneio Oficial de Robótica First Lego } \\
\text { League (FLL) - Brasil (PARANÁ, 2014) }\end{array}$ \\
\hline & $\begin{array}{l}\text { Criação do Grupo de Pesquisa em RE e Computação do Instituto Federal } \\
\text { do Sertão Pernambucano - PE. (FRANKLIN, 2015) }\end{array}$ \\
\hline \multirow[t]{2}{*}{2017} & $\begin{array}{l}\text { Primeira Conferência Scratch Brasil - Universidade de São Paulo (USP/SP). } \\
\text { (INSTITUTO AYRTON SENNA, 2017) }\end{array}$ \\
\hline & $\begin{array}{c}\text { Secretaria da Educação Básica - MEC elabora o Projeto Básico de RE - } \\
\text { Brasil. (AUDIÊNCIA PÚBLICA 4/2017, 2017) }\end{array}$ \\
\hline 2018 & $\begin{array}{l}\text { Governo Federal abre licitação à aquisição de conjuntos de RE - Brasil. } \\
\text { (MINISTÉRIO DA EDUCAÇÃO, 2018) }\end{array}$ \\
\hline
\end{tabular}

Fonte: Autoria Própria (2019).

A análise da tabela é possível observar alguns aspectos importantes na trajetória da RE no Brasil, os quais são descritos a seguir.

- Nos primeiros anos, há uma predominância de projetos voltados para linguagem e ambiente LOGO, havendo uma migração para utilização de Kits de Robótica e adoção do termo "Robótica Educacional" do final da década de 1990 para o início dos anos 2000. Essa migração pôde ser observada a partir de buscas realizadas na Biblioteca Digital de Teses e Dissertações (BDTD) ${ }^{4}$, cujos resultados encontrados foram: de 1981 a 1999, foram registradas uma pesquisa com o temática de RE e 21 pesquisas voltadas para ambiente ou linguagem LOGO; de 2000 a 2018, foram registradas 55 pesquisas no campo da RE e cinco pesquisas com o LOGO.

- A maior parte das ações é de instituições públicas, com exceção dos eventos de âmbito internacional, como o Torneio FLL, que é financiado pela LEGO.

- Grande parte dos registros se concentra em duas instituições principais, a UNICAMP e a UFRGS.

- Apesar dos kits de RE terem sido popularizados no início dos anos 2000, apenas em 2017 houve a iniciativa do Governo Federal para um plano de inclusão nas escolas públicas.

Observa-se, portanto, um desenvolvimento, não apenas nas pesquisas científicas e nos termos utilizados por elas, mas também dos aparatos físicos que partiram de uma linguagem de programação, a LOGO, passando pelo ambiente LOGO e chegando aos mais sofisticados conjuntos de RE. 


\section{CONSIDERAÇÕES FINAIS}

Neste artigo buscamos compreender os princípios por trás da RE, partindo das primeiras ideias e teorias do seu idealizador, Seymour Papert, considerando as contribuições de José Armando Valente e chegando ao conceito do RE entendido por autores da atualidade. E, por fim, buscamos entender a trajetória da RE no Brasil, a fim de conhecer as mudanças ocorridas ao longo do tempo e como chegamos à abordagem utilizada nos dias atuais.

À luz dos aspectos teóricos apresentados neste texto, podemos abarcar, não apenas como se deu o surgimento da RE, mas também quais devem ser os objetivos ao utilizá-la como ferramenta no processo de ensino e aprendizagem. Nesse sentido, a RE pode ser compreendida como um ambiente composto por diferentes artefatos que dão subsídio a uma aprendizagem significativa por meio de ações físicas e mentais realizadas pelos alunos e mediadas pelo professor. Esses artefatos podem ser físicos ou virtuais (como a Tartaruga de Papert, no LOGO) e de diferentes abordagens: kits com peças pré-fabricadas, como o LEGO; personagens nas telas dos computadores, como o Scratch; e utilização de plataformas que oferecem maior liberdade às criações, como o Arduino.

Além disso, segundo a nossa interpretação, a RE pode ser dividida em etapas que dão sentido à aprendizagem: planejamento (o aluno planeja as suas ações, criando modelos mentais), execução (monta e programa protótipos) e reflexão (reflete sobre seus acertos e erros).

Segundo o que foi possível pesquisar, identificamos, nas ideias dos autores descritas neste artigo, aspectos e intenções que caracterizam a RE como uma poderosa ferramenta de ensino e aprendizagem, podendo ser utilizada por e para diferentes públicos. Revisitar essas ideias também foi fundamental para desenvolver nossa pesquisa e consolidar os aspectos teóricos-metodológicos da mesma. Aspectos esses que trataremos em um próximo artigo. 


\title{
EDUCATIONAL ROBOTICS: UNDERSTANDING CONCEPTS
}

\begin{abstract}
The purpose of this article is to present, through a bibliographical study, the history of Educational Robotics (RE), from the point of view of Seymour Papert's Constructionist (1928-2016) and the interpretations of José Armando Valente (1948). To do so, first, an approach is made about how two book works - LOGO: computers and children and a children's machine: rethinking a school in the computer age. Following is a rereading of Valente on Constructionism - contextualized constructionism and a learning spiral. Following, it sought to understand the process of creation and development of a scientific order proposed by Papert himself, a Cybernetics, today called RE. Finally, we present projects, studies and events that make up the history of RE in Brazil and that we present ourselves as the evolutionary components, from the first studies with LOGO in the 1970s to the present day.
\end{abstract}

KEYWORDS: Educational Robotics. LOGO. Constructionism. Story. 


\section{NOTAS}

1 Esse trabalho busca verificar a potencialidade da utilização de uma ferramenta de RE de baixo custo com alunos que possuem diagnóstico de NEE e consiste, além de uma pesquisa de cunho teórico, da análise de uma oficina de RE realizada com quatro alunos da rede pública de ensino de Vitória da Conquista, Bahia. Durante a oficina, os alunos construíram uma maquete com materiais reutilizados (papelão, isopor, papel de presente, fios de internet), componentes eletrônicos (leds, resistores, sensor e motor) e uma placa de prototipação de baixo custo, o Arduino.

2 José Armando Valente iniciou seus estudos com o LOGO e o Construcionismo em 1976 quando, após convite de Papert e Minsky, foi estudar no Laoratório LOGO do MIT. As interpretações de Valente são utilizadas neste texto, não apenas por ser um estudioso do Construcionismo, mas por ser um dos principais autores que abordam o nosso tema principal "O uso dos computadores na Educação Especial".

3 Stephen Ocko trabalho no MIT Media Lab como um dos desenvolvedores da plataforma LEGO-LOGO.

4 Foram utilizados os Descritores "Robótica Pedagógica", "Robótica Educacional", "Robótica Educativa", "LOGO e Computadores" e "Linguagem LOGO".

\section{REFERÊNCIAS}

ARDUINO. O que é o Arduino?, 2019. Disponivel em: $<$ https://www.arduino.cc/en/Guide/Introduction>. Acesso em: 25 jan. 2019.

AUDIÊNCIA PÚBLICA 4/2017. Robótica Educacional. Brasília. 2017.

CAPES. Catálogo de Teses e Dissertações. Coordenação de Aperfeiçoamento de Pessoal de Nível Superior, 17 Março 2019. Disponivel em: <catalogodeteses.capes.gov.br/catalogo-teses/\#!/>. Acesso em: 16 mar. 2019.

CHAVES, E. A Informática na Educação no Brasil: Uma Vista de um Ponto. Edutec Space, 17 Março 2015. Disponivel em: <https://edutec.space/2018/04/11/ainformatica-na-educacao-no-brasil-uma-vista-de-um-ponto/>. Acesso em: 16 mar. 2019.

CITILAB. S4A. Sobre o S4A, 2015. Disponivel em: <http://s4a.cat/>. Acesso em: 25 jan. 2019.

FERNANDES, C. T.; SANTOS, N. PESQUISA E DESENVOLVIMENTO EM INFORMÁTICA NA EDUCAÇÃO NO BRASIL - Parte 1. Revista Brasileira de Informática na Educação, 1999. 
FRANKLIN, R. Sobre a GRECO. Grupo de Pesquisa em Robótica Educacional e Computação, 2015. Disponivel em: <http://greco.ifsertao-pe.edu.br/>. Acesso em: 17 mar. 2019.

INSTITUTO AYRTON SENNA. USP e MIT realizam a Conferência Scratch Brasil com apoio do Instituto Ayrton Senna, 2017. Disponivel em:

$<$ https://www.institutoayrtonsenna.org.br/content/institutoayrtonsenna/ptbr/radar/Conferencia Scratch.html >. Acesso em: 17 mar. 2019.

LEGO, G. LEGO. History of LEGO Robotics, 2018. Disponivel em: <https://www.lego.com/pt-br/mindstorms/history?ignorereferer=true $>$. Acesso em: 24 jan. 2019.

LOGO FUNDATION. LOGO FUNDATION. A Logo Primer, 2015. Disponivel em: <http://el.media.mit.edu/logo-foundation/what is logo/logo primer.html>. Acesso em: 11 nov. 2018.

LOPES, C. R. et al. Grupo de Inteligência Artificial da Faculdade de Computação da Universidade Federal de Uberlândia. Anais dos Workshops do CBIE 2014, 2014. 178.

LOPES, D. D. Q. A exploração de modelos e os níveis de abstração nas construções criativas com robótica educacional. Universidade Federal do Rio Grande do Sul. Porto Alegre, p. 327. 2008.

MARCÃO, C. I. C. Robots \& Necessidades Educativas Especiais: $O$ desenho de uma oficina de formação para a aplicação da robótica educativa em contexto inclusivo. Universidade Nova de Lisboa. Lisboa, p. 374. 2017.

MENEZES, E. T.; SANTOS, T. H. D. Verbete robótica educacional. Dicionário Interativo da Educação Brasileira - Educabrasil., 2015. Disponivel em:

$<$ https://www.educabrasil.com.br/robotica-educacional/>. Acesso em: 22 ago. 2019.

MINISTÉRIO DA EDUCAÇÃO. Pregão Eletrônico no 4/2018 - Registro de Preços Nacional. Fundo Nacional de Desenvolvimento da Educação, 16 Janeiro 2018. Disponivel em: <https://www.fnde.gov.br/acoes/comprasgovernamentais/compras-nacionais/pregoes-eletronicos/item/11348preg\%C3\%A3o-eletr\%C3\%B4nico-n\%C2\%BA-4-2018-\%E2\%80\%93-registro-depre\%C3\%A7os-nacional>. Acesso em: 17 mar. 2019. 
MODELIX Robotics. Modelix Robotics, 2018. Disponivel em:

<www.modelix.com.br/quem-somos>. Acesso em: 25 jan. 2019.

MORAES, M. C. INFORMÁTICA EDUCATIVA NO BRASIL: um pouco de história. Em Aberto, Brasília, v. 57, p. 133, 1993.

NIED. Núcleo de Informática Aplicada à Educação, 17 Março [20--?]. Disponivel em: <https://www.nied.unicamp.br/>. Acesso em: 16 mar. 2019.

NIED. Robótica Pedagógica. Núcleo de Informática Aplicada à Educação, [20--?]. Disponivel em: <https://www.nied.unicamp.br/projeto/robotica-pedagogica/>. Acesso em: 16 mar. 2019.

PAPERT, S. Logo: Computadores e educação. Tradução de José Arnaldo Valente; Beatriz Bitelman e Afira Ripper Vianna. São Paulo: Brasiliense, 1985.

PAPERT, S. A Máquina das Crianças: Repensando a Escola na Era da Informática. Tradução de Sandra Costa. Porto Alegre: Artes Médicas, 1994.

PARANÁ. Agência de Notícia da Prefeitura Municipal de Curitiba. Portal da Prefeitura de Curitiba, 17 Março 2014. Disponivel em:

$<$ http://www.curitiba.pr.gov.br/noticias/alunos-da-rede-municipal-participaraopela-primeira-vez-de-disputa-internacional-de-robotica/33948>. Acesso em: 17 mar. 2019.

PERNAMBUCO. Pernambuco sedia torneio regional de robótica FIRST ${ }^{\circledR}$ LEGO $^{\circledast}$ LEAGUE $^{\circledR}$. Secretaria de Educação do estado de Pernambuco, 17 Março 2011. Disponivel em:

$<$ http://www.educacao.pe.gov.br/portal/?pag=1\&cat=37\&art=262>. Acesso em: 17 mar. 2019.

PETE. Pete, 2017. Disponivel em: <https://www.pete.com.br/quem-somos/>. Acesso em: 25 jan. 2019.

PIAGET, J. A Epstemologia Genética. Tradução de Nathanael C. Caixeira. Petrópolis: Vozes, 1971.

QUEIROZ, L. R. D. Um Laboratorio virtual de robotica e visão computacional. Universidade Estadual de Campinas. Campinas, p. 61. 1998. 
<http://www.niee.ufrgs.br/alunos/lucila/congres.html>. Acesso em: 16 mar. 2019.

SILVA, A. F. D. RoboEduca: Uma metodologia de Aprendizado com RObótica Educacional. Universidade Federal do Rio Grande do Norte. Natal, p. 127. 2009.

SUPER logo. Núcleo de Informática Aplicada à Educação, 17 Março [20--?]. Disponivel em: <www.nied.unicamp.br/projeto/super-logo/>. Acesso em: 16 mar. 2019.

UFRGS. ROBO+EDU. UNIVERSIDADE FEDERAL DO RIO GRANDE DO SUL, 17 Março [201-?]. Disponivel em: <https://www.ufrgs.br/robomaisedu/>. Acesso em: 17 mar. 2019.

VALENTE, J. A. Liberando a mente: computadores na educação especial. Campinas: Gráfica Central da UNICAMP, 1991.

VALENTE, J. A. O Computador na Sociedade do Conhecimento. Campinas: UNICAMP/NIED, 1999.

VALENTE, J. A. A Espiral da Espiral de Aprendizagem: o processo de compreensão do papel das tecnologias de informação e comunicação na educação. Universidade Estadual de Campinas - UNICAMP. Campinas, p. 238. 2005.

VALENTE, J. A. Educom: A história do projeto Educom. Núcleo de Informática Aplicada à Educação, 2006. Disponivel em:

<https://www.nied.unicamp.br/projeto/educom/>. Acesso em: 17 mar. 2019. 
Recebido: 16 out. 2019

Aprovado: 20 abr. 2020

DOI: $10.3895 /$ rbect.v13n3.10965

Como citar: SANTOS, R. C.; SILVA, M. D. F. A robótica educacional: entendendo conceitos. Revista

Brasileira de Ensino de Ciência e Tecnologia, Ponta Grossa, v.13, n. 3, p. 345-366, set./dez. 2020.

Disponível em: <https://periodicos.utfpr.edu.br/rbect/article/view/10965>. Acesso em: XXX

Correspondência: Railane Costa Santos - raicostasantos@gmail.com

Direito autoral: Este artigo está licenciado sob os termos da Licença Creative Commons-Atribuição 4.0

Internacional. 